\title{
Study on the Fusion of Tourism and Cultural Industries
}

\author{
Meng Su ${ }^{1}$ \\ ${ }^{1}$ Oxbridge College, Kunming University of Science and Technology, Kunming, Yunnan, 650106
}

KEYWORDS: Tourism and Cultural Industry; Industry Fusion; Society Development

\begin{abstract}
Tourism is an association between the development of strong industry, the tourism industry as the main tourist attraction and tourism product development the merits or not is one of the key factors that influence the development of their industry, and the cultural and creative industries with its high added value, high integration, high brand influence, sustainable updates and other characteristics of the development of tourism provides a new value-added points. Tourism industry and the further integration of cultural and creative industries development, as the direction of future development of tourism and the most advanced form. From the perspective of integration and cultural creative industries, this paper explores the current bottleneck in the development of travel industry solution.
\end{abstract}

\section{Introduction}

As a sunrise industry in the 21st century, the development of tourism industry faces several important realities: First, greater travel demand the release: With the country under a comprehensive process of urbanization, popular materialism, work ethic too much publicity, leisure lazy people on the curb seek true way of life, stress, pressure, and other sub-health problems so that more and more people began to criticize the work ethic advocated people to return to the rational values, seeking mental and physical conditioning, pleasant city leisure and tourism activities; Second, tourism products need to be upgraded update: after three years of rapid tourism development, people's travel consumer is basically over hungry tourist stage, about to enter the well-off tourist stage, experience tourism, cultural tourism, special tourism more and more people of all ages. Cultural tourism has experience and creative characteristics of tourism and socio-economic, and cultural development of multiple advanced form of tourism driven, and most of the current level of development of cities and regions in cultural, economic and tourism has become the cultural and creative experiential tourism implementation provides adequate conditions; Third, the industry suffered resource endowment constraints: the tourism industry for sustainable use of smokeless industry, tourism economic development of the country set off a craze, but because tourism planning is unreasonable, excessive development of tourism resources tourism and protection measures to promote tourism and other factors adversely waste of resources, destruction and pollution, cultural resource assimilation phenomenon reflects environment Everyday, by water draft resource sharing shaping industrial development model has become a bottleneck in the development of tourism. So, faced with the huge demand for travel and tourism needs new depth, looking for new breakthroughs in the development of tourism has become an urgent problem to be solved. 
Consumer definition of tourism. Consumer definition of tourism consumption is defined in terms of material goods and services from tourists. In 1971 the United Nations General Assembly of the earliest definitions of tourism: Tourism is the sum of domestic and international tourists to meet consumption, providing a variety of products and services to business enterprises; Powell in 1978: the tourism industry and includes dual responsibility to meet the needs of society, including its production to meet the needs of tourists and features a variety of travel experiences and services; including tourism Le Paer also made to meet all the needs of travelers of various companies, organizations and tourist facilities in 1979; its editor in the field Introduction of modern tourism 56 proposes: Tourism is conducted tours and excursions for tourists provide a variety of product and service charge of industry, it is by virtue of tourism resources, tourism facilities for the material conditions provide tourists a series of associated industries a variety of commercial and personal services.

The functional definition of tourism. Functional definition of tourism is in accordance with the degree of providing products and services to tourists to define tourism. Japanese scholars thick Doi asked: Tourism is a series of interrelated services sectors for domestic and foreign tourists. Tourism related to passengers, travel, accommodation and other facilities supply a variety of things; Chinese scholars Liu Wei, Zhu Yuhuai considered: generalized tourism refers to the virtue of tourism resources, tourism facilities as a condition for people to trip IT tour service, to obtain economic benefits from all industries and sectors, including the hotel industry, travel industry, transportation, light industry, commerce, telecommunications, finance and insurance, and food and beverage industries.

For this theory frontier industrial integration industrial economics, scholars are to be a lot of attention, but so far did not achieve consensus. Overall summarize, there are defined two aspects: First, the narrow concept, that is, from the perspective of information technology exposition, more representative definition: European Commission Green Paper is defined as the integration of industry and industry alliance fusion three angles, such as cooperation, technology and market network platform; our economist Zhou Zhenhua proposes industrial integration is an economic phenomenon occurring in the information process. With the development of information technology and the widespread use of the Internet in particular the formation and maturation first immobilized industry boundaries blur and disappear fusion phenomenon appears in telecommunications, radio, television and publishing sector in the 1990s.

\section{System 3 tourism industry and cultural and creative industries Fusion}

Cultural and creative industries and the tourism industry is the basis of cultural and creative industries produced by fusion, is the biggest difference between fusion and other industries where its internal effect of natural factors affecting the production and development of the tourism industry and cultural and creative industries integration.

First, the development of cultural and creative industry park is actually a product of industrial clustering, some industries can produce, display, and sales in the same parks and other enterprises to form a cluster, plus living ancillary facilities within the park to become whole, greening and infrastructure. This development makes the original function does not have the tourist area of production and sales has become sightseeing, leisure, place of learning, tourism industry and cultural and creative industries permeable fusion, this generally has a scenic tour of production and dual-use capabilities, usually does not affect the production of the tour, but often will produce as a tourist selling point. Such as: animation film base and industrial park. 
The second increase, exhibition and other festivals and showcase the most positive factor is the tourism industry and the integration of cultural and creative industries to get promoted. It is not only the performance of popular cultural and creative industries, but also provides a platform for public participation to promote effective public awareness of this form.

Third, the resort development of cultural and creative industries explicitly cultural and creative industries and tourism industry convergence is the most actively direct the force of industry convergence. This resort is mainly through the construction of a theme park in the form of specialized attracts tourists, it is the most direct expression of cultural and creative industries and tourism industry integration. Such as: Disneyland.

\section{To Method to Promote China's Tourism Industry}

In general, the industry can be described as the process of birth: Science - Technology - Product Development - channel business - market - industry. From the birth of the industry can be found in the formation of industry boundaries actually contains from technology to product, from business to markets multidimensional boundary. Similarly, the entire process is simplified from the industrial and economic activities, the starting point of economic activity begins technology industry, and finally the product. Thus, the distinction between different industries, industrial and economic activities in the border also relates to the border technologies, products, services and markets multi-level content. Therefore, to promote the tourism industry and the integration of cultural and creative industries development needs under the guidance of the concept of industrial integration, breaking technologies, products and market boundaries in this technology talent borders mainly caused by the convergence of the two industries to achieve the measures can be summarized by breaking ideas, talent, products and markets leaving four boundaries of cultural and creative tourism.

A network service is to increase public exposure. With the improvement of digital and network technology and the rapid development of people's living standards, China's Internet penetration continues to increase, according to the latest statistics of China Internet development report by the China Internet Network Information Center (CNNIC) released the first 21 times today baked, as of 27 December, the number of Internet users has increased to 210 million people. Slightly lower than the current number of Internet users in China 210 million US, in second place in the world. Application of cultural and creative industries in the field of network services has become an important way to foster a way of cultural and creative products of cognitive and raising public awareness of cultural and creative products receiving power. Through the construction of digital TV broadcasting information platform, digital cinema network systems, virtual libraries, virtual museums, theaters and creative web forums remote mentoring to advocacy networks. This greatly broadens the public's understanding of the cultural and creative tourism industry for the development of cultural and creative tourism industry diversification, popularity and popularity of offers great possibilities.

Government plays in the integration of the tourism industry and the cultural and creative industries in a huge boost, which plays three roles: In the early stages of planning the tourism industry and the integration of cultural and creative industries, the government can take advantage of the administrative system of the mobilization of economic resources, the establishment of many of the cultural and creative industrial park and tourism functionality into the park development, or government-led build a variety of cultural and creative tourism platform; tourism industry and cultural and creative industries fusion process, two important constraint is the intellectual property, copyright maintenance issues Government must introduce a series of laws and regulations, the 
tourism industry and the integration of cultural and creative industries play a very good run health regulatory role. In coordinating all social forces, various ways to encourage business development, protect the interests of consumers and the overall cultural and creative tourism image promotion, improve the cultural and creative tourism environment to address cultural and creative industries and the tourism industry and other trade barriers, the Government is It plays an irreplaceable role.

Create an inclusive ecological environment suitable to generate creative culture. Contemporary society to unprecedented infrastructure in the past, so that the creative economy to flourish. The reason why the American creative economy flourished because of its strong creative social structure (The Social Structure of Creativity) as the support include: Science and Technology for creativity and new enterprise system (for example, interested in the creative industries to invest the financial system, the development of high-tech companies, the continued growth of research costs, etc.); innovation and more efficient goods and services production model (for example, employees can play a creative work environment, flexible production, etc.); and conducive to creative social, cultural and geographical environment ( for example, to attract creative people Diao - lifestyle or encouraging cultural institution avant-garde art, etc.). This creative social structure may be suitable as a cultural ecology and creative industries thrive, prerequisite for the development of creative industries is committed to building the ecological environment of this creative industry, that is, by building the cultural creativity into capital intermediary platform, cultural creation, cultural resources, cultural accumulation of the product; by building innovative products industry promotion mechanism, raising the cultural spirit and creative industries, the integration of cultural resources and creative industries, realize the market value of creative industries.

\section{Conclusion}

From the perspective of integration and cultural and creative industries, this paper explores the current bottleneck in the development of travel industry solution. The author in-depth understanding of the connotation of cultural and creative industries and its development in the world, the use of industry convergence theory analysis fusion mechanism of the tourism industry and the cultural and creative industries, and to put forward three kinds of integration and development mode, based on this and the cultural and creative industry value chain integration of the analysis, in addition to exploring the development of an interactive two industrial integration. Then, by constructing a model of tourism industry development system and the integration of cultural and creative industries Analysis of Supply - Demand - Support - government - the role of environmental factors in five areas; then, from the four aspects of demand and supply, the government and the Environment of the country to promote tourism industry and cultural and creative industries integration strategies to achieve economic growth of the tourism industry in transition.

\section{REFERENCE:}

[1] Huang-Yuan S . Speculative Absence Disease Foreign Language Teaching [J]. 1998(7): 16-19.

[2] Wen-Qiu F, Wang-Jian Q, l. Measuring the Ability of Speculative Foreign Language Class Students Construct a the Oretical framework[J]. Western Circles Culture, 2009 (1): 37-43.

[1] Juan L.Paramio and JoséL.Zofío The Evolution of the Labor Market and Leisure Industries In Spain:.. Quality of Life versus Standard of Living Working Paper 6,2008.

[2] Michael Watkins Ways of Experiencing Leisure Leisure Sciences, 29:.. 285-317,2007

[3] Stephen G.Jones. Trends in the Leisure Industry since the Second World War. P323-355. 
[4] Snape, R (2004) The Co-operative Holidays Association and the cultural formation of countryside leisure practice. Leisure Studies, 23 (2), 140-156. 